\title{
Efficacy and adherence of auto-CPAP therapy in patients with obstructive sleep apnea: a prospective study
}

\author{
Hang Dinh-Thi-Dieu, ${ }^{1}$ Anh Vo-Thi-Kim, ${ }^{2}$ Huong Tran-Van, ${ }^{2}$ Sy Duong-Quy ${ }^{3,4}$ \\ ${ }^{1}$ Hai Duong Medical Technical University, Hai Duong city, Vietnam \\ ${ }^{2}$ Department of Public Health, Thang Long University, Hanoi, Vietnam \\ ${ }^{3}$ Clinical Research and Sleep Lab Centers. Lam Dong Medical College, Da Lat city, Vietnam \\ ${ }^{4}$ Hershey Medical Center, Penn State Medical College, Hershey, PA, USA
}

Introduction: The use of auto-continuous positive airway pressure (auto-CPAP) therapy has been recommended for subjects with moderate-to-severe obstructive sleep apnea (OSA) without significant comorbidities. This study is aimed at evaluating the efficacy and adherence of auto-CPAP therapy in subjects with OSA.

Methods: It was a perspective and descriptive study. All study subjects who had apnea-hypopnea index $($ AHI $)>30 / \mathrm{h}$, measured by polysomnography, were included. They were treated with auto-CPAP and followed-up for 6 months for evaluating the effect of CPAP-therapy on clinical and biological features and treatment adherence.

Results: One hundred and thirty-nine subjects with severe OSA were accepted for auto-CPAP therapy at inclusion. BMI was $28.4 \pm 3.8 \mathrm{~kg} / \mathrm{m}^{2}$; neck and abdomen circumferences were 38.2 \pm 6.4 and $85.7 \pm 11.6$. Epworth and Pichot scores were $18.4 \pm 6.3$ and $28.3 \pm 4.5$, respectively; AHI was $39 \pm 7 / \mathrm{h}$ and arousal index was $39 \pm 13 / \mathrm{h}$. At $6^{\text {th }}$ month, $96.4 \%$ of study subjects continued to use auto-CPAP-therapy within $6.5 \pm 2.4 \mathrm{~h} /$ night. There was a significant correlation between the modification $(\Delta)$ of Epworth scores and $(\Delta)$ AHI after 3 and 6 months of auto-CPAP-therapy $(\mathrm{R}=0.568$ and $p=0.003 ; \mathrm{R}=0.745$ and $p=0.002$; respectively). At $6^{\text {th }}$ month follow up, the main side effects of auto-CPAP were difficult sleeping, dry mouth or nose, skin marks or rashes, discomfort when breathing, and nasal congestion (36.1\%, $32.0 \%, 20.8 \%, 16.0 \%$, and $11.9 \%$, respectively).

Conclusion: Auto-CPAP is effective in treatment of Vietnamese patients with severe OSA in short term follow up.

Key words: Obstructive sleep apnea; apnea-hypopnea index; Epworth; Pichot; Auto-CPAP.

Correspondence: Pr. Sy Duong-Quy, Director of Sleep Lab and Clinical Research Centers. Lam Dong Medical College, Hershey Medical Center, Penn State Medical College, 700 HMC Cres Rd, Hershey, PA 17033, USA.

E-mail: sduongquy.jfvp@gmail.com

Contributions: HDTD, HTV, SDQ, work concept and design; HDTD, AVTK, acquisition, interpretation and analysis, manuscript drafting, review and editing. All Authors read and approved the final version and agreed, both to be personally accountable for the author's own contributions and to ensure that questions related to the accuracy and integrity of any part of the work, are appropriately investigated, resolved, and the resolution documented in the literature.

Conflict of interest: The Authors declare no conflict of interest.

Funding: The study was supported by the Grant from Lam Dong Medical College (LDMC-SR.042.2016). Da Lat city, Vietnam.

Availability of data and materials: The datasets used and/or analyzed during the current study are available from the corresponding author on reasonable request.

Ethics approval and consent to participate: The study was conducted in accordance with the Declaration of Helsinki, and the protocol was approved by the Ethics Committee of Lam Dong Medical College Institutional Review Board (no. CDYTLD.04.16). All study subjects had signed Informed Consent approved by Institutional Review Board (IRB) of Lam Dong Medical College.

Consent for publication: Not applicable. 


\section{Introduction}

Obstructive sleep apnea (OSA] is one of the sleep disorders affecting a large number of population worldwide [1-3]. OSA is manifested mainly by snoring associated with episodes of interrupted breathing due to the partial or total collapse of upper airways during sleep [4]. The recovery of normal breathing from apnea-hypopnea episodes during sleep occurs after respiratory efforts within arousal, resulting in sleep fragmentation, sleep quality impairment, and daytime sleepiness. In addition, OSA with intermittent hypoxia that happens during sleep, increases oxidative stress production, cardiovascular events, and metabolic disorder $[5,6]$. For subjects with OSA, the accurate treatment according to pathophysiology is to maintain the opening of upper airways during sleep.

Since 1981, when the first publication of OSA treatment with continuous positive airway pressure (CPAP) was published, this method is considered as standard therapy for symptomatic or moderate-to-severe OSA, diagnosed by polysomnography (PSG) with apnea-hypopnea index (AHI) $>15 / \mathrm{h}$ [7-9]. Previous studies showed that in subjects with OSA treated by CPAP there was a significant improvement of daytime sleepiness and fatigue, nocturia, snoring, and quality of life $[10,11]$. CPAP therapy also improves the cardiovascular events and the risk of traffic accidents $[12,13]$.

The current guidelines recommend overnight PSG for the diagnosis of OSA and laboratory-titrated CPAP for treatment of subjects with OSA [13-16]. However, in-laboratory titration CPAP therapy is labor intensive, expensive, and burdensome. Previous studies also demonstrated the beneficial role of auto-CPAP therapy in treatment of patients with OSA [17-19]. Therefore, in emerging countries where the number of sleep laboratories is very limited, the use of auto-adjusting CPAP at home might be an alternative method for treatment of subjects with OSA. The present study was conducted to evaluate the efficacy and side effects of auto-CPAP in patients with severe OSA and their adherence.

\section{Methods}

\section{Patients}

All adult subjects with severe OSA diagnosed by PSG (AHI $>30 / \mathrm{h}$ ) and treated with CPAP were included in the present study after meeting the inclusion criteria. All subjects gave their informed consent for inclusion before they participated in the study. The study was conducted in accordance with the Declaration of Helsinki, and the protocol was approved by the Ethics Committee of Lam Dong Medical College Institutional Review Board.

\section{Inclusion criteria}

Subjects more than 18 years old who were diagnosed with severe OSA (AHI $>30 / \mathrm{h}$ ) without significant comorbidities (congestive heart failure, chronic respiratory failure such as severe chronic obstructive pulmonary disease, neuromuscular disease, hypoventilation syndrome, or central sleep apnea) and accepted to be treated with auto-adjusting CPAP (thereafter auto-CPAP) were included in the present study.

\section{Exclusion criteria}

Subjects with moderate-to-severe OSA who had one of the following comorbidities or conditions were excluded from the present study: congestive heart failure, significant chronic respiratory diseases such as uncontrolled asthma or chronic obstructive pulmonary disease, neuromuscular disease, central sleep apnea syndrome, or chronic opiate use.

\section{Study design}

It was a perspective and descriptive study. The anthropometric and clinical, functional, and biological parameters were recorded for analysis. All study subjects underwent clinical examination, lung function testing for eliminating other obstructive airway diseases, biochemical blood tests, and PSG. The questionnaire about symptoms of OSA, sleep habit and quality, snoring at night, daytime sleepiness and tiredness were completed by study subjects. The severity of daytime sleepiness and tiredness were assessed by Epworth sleepiness scales (0-24 points) and Pichot tiredness scales (0-32) for each patient [20,21]. The severity of OSA was assessed by AHI (mild: $5-14 / \mathrm{h}$, moderate: $15-30 / \mathrm{h}$, and severe $>30 / \mathrm{h}$ ). All subjects with moderate-to-severe OSA were treated by auto-CPAP and setting $\min -$ max pressures were 4-20 $\mathrm{cmH}_{2} \mathrm{O}$, respectively. The use of patients' interface (nasal or facial mask) depended on own choice after auto-CPAP-therapy trying.

\section{Laboratory techniques}

Lung function testing (LFT): LFT was done by Body Box 500 (Medisoft, Sorinnes, Belgium) for whole-body phlethysmography. For subjects with respiratory obstructive disorders (Forced expiratory volume in one second - $\mathrm{FEV}_{1} /$ forced vital capacity - FVC $<0.70$ ), the bronchial reversibility was evaluated after $15 \mathrm{~min}$ using $400 \mathrm{mcg}$ of salbutamol in MDI as recommended by American Thoracic Society (ATS)/European Respiratory Society (ERS) [22].

Polysomnography (PSG): In-laboratory overnight PSG was performed for each study subject as recommended by the American Academy of Sleep Medicine (AASM) and previously described [7,15]. PSG was done for each study subject with the use of Alice PSG (Philips, USA). The recording time was from 9 PM to $6 \mathrm{AM}$ of the day after. The recorded parameters were electroencephalography (EEG), chin electromyography (EMG), electrocardiography (ECG), nasal and oral air flows, thorax-abdomen movements, sleeping posture, apnea-hypopnea index (number/h), type of apnea (central, obstructive, or mixed apnea), mean oxygen saturation $\left(\mathrm{SpO}_{2}\right)$, and minimum $\mathrm{SpO}_{2}$ (nadir $\left.\mathrm{SpO}_{2}\right)$. The severity of OSA was defined by AHI as mild OSA (AHI $=5-15 / \mathrm{h})$, moderate OSA $(\mathrm{AHI}=16-30 / \mathrm{h})$, or severe OSA $(\mathrm{AHI}>30 / \mathrm{h})$. Subjects with severe OSA who were eligible for inclusion criteria, were included in the present study for auto-CPAP therapy.

Auto-adjusting CPAP at home: Eligible study subjects underwent an unattended automatically adjusting CPAP (auto-CPAP) titration at home by using the REMstar Auto (Philips-Respironics, Murraysville, PA, USA) or RESMED AutoSet S9 (ResMed, Bella Vista, Australia). The pressure was set to start automatically, ranging from $4 \mathrm{~cm}$ of water pressure (cwp) up to a maximum of 20 cwp. Sleep laboratory staff was in contact directly or indirectly by telephone with study subjects during the first week auto-titration and for troubleshooting. During the home-based auto-PAP, study subjects completed a basic sleep checklist indicating at what time they fell asleep and when they woke up as described previously [19]. The successful auto-CPAP therapy was defined by residual AHI $<5 / \mathrm{h}$ with optimal pressure, measured by the device algorithm.

\section{Statistical analyses}

All recorded parameters were analyzed by using IBM-SPSS 22.0 software (Chicago, IL, USA). Categorical variables were expressed as numbers or percentages. Continuous variables were presented as mean $\pm \mathrm{SD}$. Normal distribution was tested by using the Skewness-Kurtosis manner. Mann-Whitney U test was used for mean pair-comparison between two groups and Kruskal-Wallis test was used for pair comparison of more than two groups. $p<0.05$ was considered as significant difference. 


\section{Results}

\section{Characteristics of study subjects with OSA}

From January 2015 to January 2018, 139 subjects with diagnosed severe OSA who accepted to be treated with auto-CPAP were included in the present study. The mean age of study subjects was $51.3 \pm 16.4$ years with male/female ratio of 3.2. The mean BMI was $28.4 \pm 3.8 \mathrm{~kg} / \mathrm{m}^{2}$ and neck and abdomen circumferences were $38.2 \pm 6.4$ and $85.7 \pm 11.6$, respectively (Table 1). The Epworth scores and Pichot scores were $18.4 \pm 6.3$ and $28.3 \pm 4.5$, respectively. The means of SBP (systolic blood pressure) and DBP (diastolic blood pressure) of study subjects were higher than normal level $(152 \pm 28 \mathrm{mmHg}$ and $94 \pm 12 \mathrm{mmHg}$; respectively). $84 \%$ of study subjects had one of other comorbidities (Table 1). There was no respiratory obstructive disorder in these study subjects in LFT (lung function testing). The mean AHI was $39 \pm 7 / \mathrm{h}$ with arousal index (ARI) of $39 \pm 13 / \mathrm{h}$. The levels of glucose, total cholesterol, LDL cholesterol, and triglycerides were higher than normal limits (Table 1).

\section{Modification of study subjects' characteristics after auto-CPAP therapy}

There was no significant difference concerning anthropometric parameters of study subjects at inclusion at $3^{\text {rd }}$ month and $6^{\text {th }}$ month after auto-CPAP therapy (Table 2). The means of SBP and DBP were significantly decreased after auto-CPAP. The Epworth and Pichot scores were significantly ameliorated at $3^{\text {rd }}$ month and $6^{\text {th }}$ month in the comparison to at inclusion (Epworth: 12.6 \pm 4.5 and $8.8 \pm 4.6$ vs 18.4 \pm 6.3 ; Pichot: $21.2 \pm 5.3$ and $25.4 \pm 4.7$ vs $28.3 \pm 4.5$, respectively; Table 2 and Figure 1). The levels of glucose and total cholesterol and LDL were significantly decreased after $6^{\text {th }}$ month of auto-CPAP therapy. The AHI registered by auto-CPAP machine was significantly reduced at $3^{\text {rd }}$ month and $6^{\text {th }}$ month under autoCPAP therapy, compared to that measured by PSG at inclusion ( $12 \pm 6$ and $7 \pm 3$ vs $39 \pm 7 ; \mathrm{P}<0.001$ and $\mathrm{P}<0.001$, respectively; Figure 1). At inclusion, there was $61.8 \%$ of study subjects who chose nasal mask but after $3^{\text {rd }}$ and $6^{\text {th }}$ month there was only $52.9 \%$ and $50.7 \%$ of them using nasal mask respectively due to air leaking through the mouth (Table 2).

\section{Correlation among modification of AHI, clinical and biological parameters}

The result showed that there were significant correlations for the modifications of $\mathrm{AHI}(\Delta \mathrm{AHI})$ and $\Delta$ Epworth scores and $\Delta$ Pichot scores at inclusion and after $3^{\text {rd }}-6^{\text {th }}$ month (Figure 2). The correlation between $\Delta \mathrm{AHI}$ and $\Delta$ Epworth scores at $6^{\text {th }}$ month $(\Delta$ [inclusion $-6^{\text {th }}$ month]) was higher than that between $\Delta$ [inclusion $-3^{\text {rd }}$ month] $(\mathrm{R}=0.745$ and $p=0.002$ vs $\mathrm{R}=0.568$ and $p=0.003$; Figure 2). There were no significant differences among $\triangle \mathrm{AHI}$ and the modifications of blood pressures, fasting glucose, total cholesterol or LDL at inclusion $v s 6^{\text {th }}$ month $(\mathrm{R}=0.236$ and $p=0.132$; $\mathrm{R}=0.105$ and $p=0.168 ; \mathrm{R}=0.098$ and $p=0.087 ; \mathrm{R}=0.118$ and $p=0.134$, respectively).

\section{Comparison of auto-CPAP adherence at $3^{\text {rd }}$ and $6^{\text {th }}$ month of study subjects}

The result showed that the percentage of study subjects who used auto-CPAP therapy at night $<30$ days/month (but $>20$ days/month) was $20.5 \%$ at $3^{\text {rd }}$ month and reduced significantly to $8.8 \%$ at $6^{\text {th }}$ month $(p<0.01$; Table 3$)$. After 6 months, the number of days with auto-CPAP usage at night in study subjects was higher than that after 3 months but it was not significantly different (26.6 \pm 1.8 vs $25.4 \pm 2.2 ; p>0.05)$. The percentage of study subjects who used auto-CPAP therapy from $4-5 \mathrm{~h} /$ night at $6^{\text {th }}$ month was
Table 1. Characteristics of study subjects with OSA at inclusion.

\begin{tabular}{|c|c|c|c|}
\hline \multirow[t]{2}{*}{ Characteristics } & \multicolumn{3}{|c|}{ Subjects with OSA (n =139) } \\
\hline & Mean \pm SD & Min-Max & $95 \% \mathrm{CI}$ \\
\hline \multicolumn{4}{|l|}{ Anthropometric parameters } \\
\hline Age, years & $51.3 \pm 16.4$ & $35-67$ & $47.5-56.7$ \\
\hline Male/female, ratio (n) & $3.2(106 / 33)$ & - & - \\
\hline Height, $\mathrm{cm}$ & $162.3 \pm 7.4$ & $155-178$ & $158.3-166.4$ \\
\hline Weight, kg & $68.5 \pm 12.3$ & $55-82$ & $65.7-72.8$ \\
\hline BMI, kg/m² & $28.4 \pm 3.8$ & $24.5-2.5$ & $26.6-30.3$ \\
\hline Neck circumference, $\mathrm{cm}$ & $38.2 \pm 6.4$ & $32-45$ & $35.7-41.2$ \\
\hline Abdomen circumference, $\mathrm{cm}$ & $85.7 \pm 11.6$ & $74-98$ & $82.5-89.6$ \\
\hline \multicolumn{4}{|l|}{ Clinical symptoms } \\
\hline Smoking, $\%$ & 32.4 & - & - \\
\hline Snoring, $\%$ & 88.2 & - & - \\
\hline Epworth scores, $(0-24)$ & $18.4 \pm 6.3$ & $12-24$ & $16.7-21.4$ \\
\hline Pichot scores*,$(0-32)$ & $28.3 \pm 4.5$ & $24-32$ & $16.5-30.2$ \\
\hline \multicolumn{4}{|l|}{ Blood pressures } \\
\hline SBP, mmHg & $152 \pm 28$ & $124-180$ & $147-156$ \\
\hline DBP, mmHg & $94 \pm 12$ & $80-110$ & $89-97$ \\
\hline Comorbidities $^{\circ}, \%$ & 84 & - & - \\
\hline \multicolumn{4}{|l|}{ Lung function parameters } \\
\hline $\mathrm{FEV}_{1}, \%$ predicted & $86.4 \pm 8.5$ & $78-95$ & $83.6-90.2$ \\
\hline FVC, \% predicted & $88.7 \pm 9.3$ & $78-98$ & 86.3-89.6 \\
\hline $\mathrm{FEV}_{1} / \mathrm{FVC}, \%$ & $77.4 \pm 6.7$ & $70-82$ & $74.5-81.4$ \\
\hline TLC, \% predicted & $89.3 \pm 7.4$ & $82-98$ & $86.4-92.7$ \\
\hline \multicolumn{4}{|l|}{ Polysomnography parameters } \\
\hline AHI, numbers/h & $39 \pm 7$ & $32-69$ & $45.5-51.6$ \\
\hline ARI", numbers/h & $39 \pm 13$ & $25-54$ & $36.7-42.8$ \\
\hline Mean $\mathrm{SpO}_{2}, \%$ & $87 \pm 4$ & $84-91$ & $85.2-89.9$ \\
\hline Nadir $\mathrm{SpO}_{2}, \%$ & $79 \pm 6$ & $72-84$ & 77.4-82.1 \\
\hline \multicolumn{4}{|l|}{ Biological parameters } \\
\hline Glucose, $\mathrm{mmol} / \mathrm{L}$ & $6.6 \pm 0.8$ & $6.2-7.4$ & $6.2-6.9$ \\
\hline Total cholesterol, mmol/L & $6.3 \pm 0.9$ & $5.2-7.1$ & $5.9-6.5$ \\
\hline LDL cholesterol, mmol/L & $4.1 \pm 0.8$ & $3.3-4.9$ & $3.8-4.3$ \\
\hline Triglycerides, $\mathrm{mmol} / \mathrm{L}$ & $2.7 \pm 0.5$ & $2.2-3.2$ & $2.5-2.9$ \\
\hline
\end{tabular}

OSA, obstructive sleep apnea; CI, confidence interval; BMI, body mass index; $\mathrm{FEV}_{1}$, forced expiratory volume in $1 \mathrm{~s}$; FVC, forced vital capacity; TLC, total lung capacity; PSG, polysomnography; AHI, apnea-hypopnea index; ARI, arousal index; LDL, low-density lipoprotein; *Pichot scores for tiredness; ${ }^{\circ}$ having at least one comorbidity (hypertension, diabetes mellitus, coronary disease, atrial fibrillation); "measured by Alice PSG auto report.

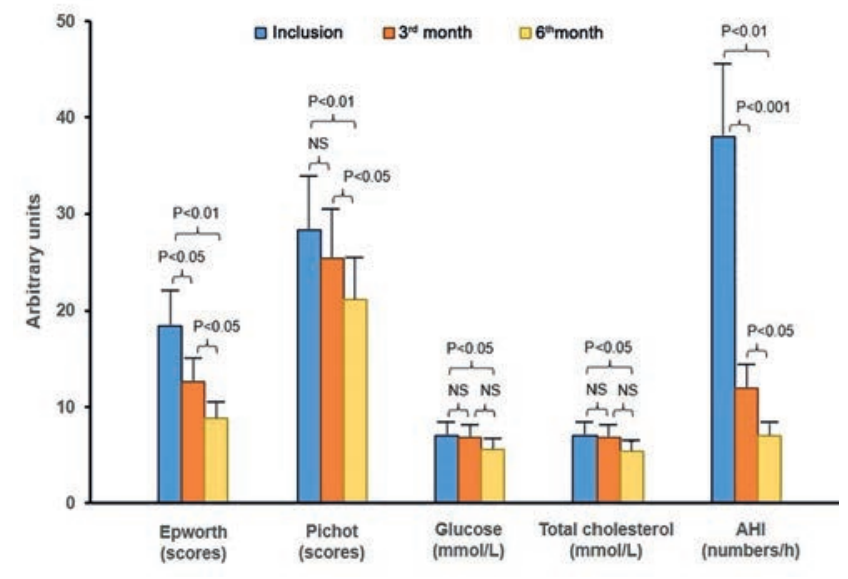

Figure 1. Modification of clinical and biological parameters of study subjects treated with auto-CPAP. OSA, obstructive sleep apnea; CPAP, continuous positive pressure; AHI, apnea-hypopnea index. 
significantly higher than that at $3^{\text {rd }}$ month $(39 \pm 4$ vs $28 \pm 3 ; p<0.05$; Table 3$)$. At $6^{\text {th }}$ month, the mean duration of auto-CPAP therapy at night was significantly higher than that at $3^{\text {rd }}$ month $(6.5 \pm 2.4 \mathrm{vs}$ $5.2 \pm 2.2 \mathrm{~h} ; p<0.05$; Table 3 ). The number of AHI registered automatically by auto-CPAP machine at $6^{\text {th }}$ month was significantly lower than that at $3^{\text {rd }}$ month $(7 \pm 3 v s 12 \pm 6 ; p<0.05)$.

Among study subjects, there were 74 subjects with severe OSA who started to be treated with REMstar Auto and 65 subjects treated with Autoset S9 at inclusion; after 3 and 6 months, there were 72 subjects treated with REMstart vs 64 subjects treated with Autoset S9 and 72 subjects treated with REMstart vs 62 subjects treated with Autoset S9, respectively. There was no significant difference between the two groups of subjects treated with the two kinds of auto-CPAP for efficiency (residual AHI index) and adherence (days and hours with auto-CPAP used at night and side effects) after $3^{\text {rd }}$ month and $6^{\text {th }}$ month.

\section{Comparison of auto-CPAP side effects at $3^{\text {rd }}$ and $6^{\text {th }}$ month in study subjects}

The main side effects of auto-CPAP therapy at $3^{\text {rd }}$ month were dry mouth or nose, difficult sleeping, skin marks or rashes, and discomfort breathing $(78.6 \%, 65.4 \%, 41.1 \%$, and $25.7 \%$, respectively; Table 3). The other side effects with lower percentage were nasal congestion, dry eyes, aerophagy or flatulence, and claustrophobia $(13.2 \%, 11 \%, 7.3 \%$, and $1.4 \%$, respectively; Table 3$)$. At $6^{\text {th }}$ month, the percentage of the main side effects such as dry mouth or nose, difficult sleeping, skin marks or rashes, and discomfort breathing were reduced significantly $(p<0.001, p<0.001, p<0.001$, and $p<0.05$ ). There were no significant differences for other minor side effects such as nasal congestion, dry eyes, aerophagy or flatulence, or claustrophobia between $3^{\text {th }}$ month and $6^{\text {th }}$ month (Table 3 ).

\section{Discussion}

The results of the present study showed that: 1) Daytime symptoms of severe OSA, measured by Epworth and Pichot scores, were significantly improved after 3 and 6 months of auto-CPAP therapy and associated with the correlation of $\Delta$ values of AHI; 2) biological disorders in subjects with severe OSA were ameliorated after 6 months of auto-CPAP therapy; 3) subjects with severe OSA had an acceptable adherence with auto-CPAP therapy with some side effects related to CPAP machine and interface devices.
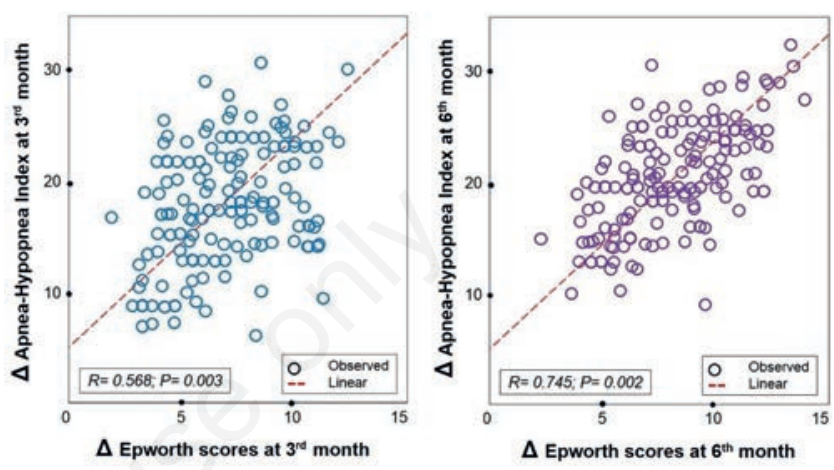

Figure 2. Correlation between delta $(\Delta)$ Epworth scores and $\triangle \mathrm{AHI}$ at $3^{\text {rd }}-6^{\text {th }}$ month vs at inclusion in study subjects treated with auto-CPAP. AHI, apnea-hypopnea index; CPAP, continuous positive pressure.

Table 2. Characteristics of study subjects at inclusion and after being treated with auto-CPAP therapy.

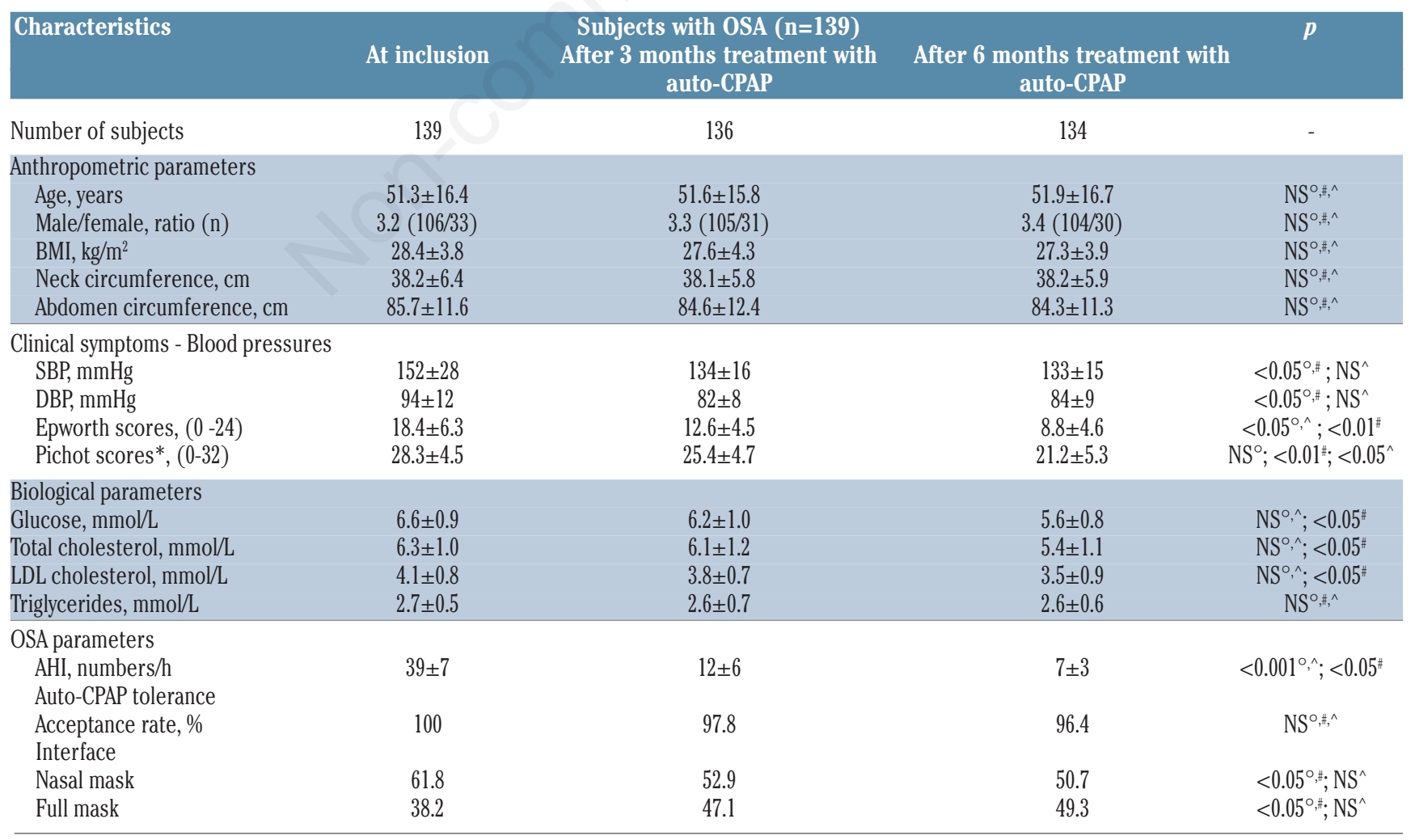

OSA, obstructive sleep apnea; CPAP, continuous positive pressure; BMI, body mass index; SBP, systolic blood pressure; DBP, diastolic blood pressure; LDL, low-density lipoprotein; AHI, apnea-hypopnea index; *Pichot scores for tiredness; ${ }^{\circ} 3^{\text {rd }}$ month $v$ inclusion; ${ }^{* \text { th }}$ month $v$ inclusion; ${ }^{\wedge} 6^{\text {th }}$ month $v s 3^{\text {rd }}$ month. 
The present study showed that study subjects with severe OSA had the typical symptoms of OSA with daytime sleepiness and tiredness (Table 1). These symptoms were evaluated objectively by Epworth and Pichot scores. Beside these symptoms, they also had high blood pressure (HBP). HBP is a very common symptom in subjects with OSA and the mechanism of the relationship between OSA and HBP has been still discussed [23,24]. It might be mainly due to the increase of sympathetic activity at wake up due to intermittent hypoxia during sleep [25]. In addition, in the present study, the subjects with severe OSA had also the biological characteristics of metabolic disorders with increasing fasting glucose, total cholesterol and LDL cholesterol (Table 1). Previous studies have also reported glycemic and lipid disorders in non-obese OSA patients and that was correlated with sleep fragmentation or severity of nocturnal hypoxia $[26,27]$. These authors suggested that metabolic status could be disrupted in OSA even in the absence of obesity.

In the present study, at inclusion, there were 139 study subjects with severe OSA who accepted to do auto-CPAP therapy at home; but after 3 months, 136 subjects $(97.8 \%)$ followed this treatment while three subjects had withdrawn auto-CPAP therapy due to the adherence problem related to discomfort breathing. For subjects with auto-CPAP therapy, the use of CPAP at night helped to improve OSA-related symptoms during the day with a significant reduction of Epthworth and Pichot scores after 3 months of follow up (Table 2). However, the improvement of biological disorders concerning high levels of fasting glucose, total cholesterol and
LDL was only improved after 6 months of auto-CPAP therapy (Table 2; Figure 1). The role of CPAP therapy in patients with severe OSA has been demonstrated in many studies. The favorable effect of CPAP therapy in reduction of blood pressure $[28,29]$ and its beneficial effect on metabolic syndrome have been reported [30,31]. However, there are few studies comparing the effect of auto-CPAP and fixed-CPAP on metabolic syndrome in subjects with severe OSA. In patients with severe OSA, the metabolic syndrome has been known as the consequence of OSA and it has been related to oxidative stress produced by intermittent hypoxia during sleep. The result of the present study showed that the biological disorder was improved later than clinical symptoms. Interestingly, there was a significant correlation between the level of AHI modification $(\triangle \mathrm{AHI})$ and $\triangle$ Epworth scores after 3 and 6 months with auto-CPAP therapy (Figure 2).

The present study showed that auto-CPAP therapy in shortterm follow up ( 6 months) had a good adherence from patients with severe OSA. After 3 months and 6 months of auto-CPAP therapy, three subjects (at $3^{\text {rd }}$ month) and then two more subjects (at $6^{\text {th }}$ month) refused to use the CPAP machine due to the problem of uncomfortable sleep at night. The result concerning auto-CPAP therapy at $3^{\text {rd }}$ and $6^{\text {th }}$ months showed that the side effects were improved over the time with acceptable tolerance (Table 3 ). At $3^{\text {rd }}$ month of auto-CPAP therapy, more than $50 \%$ of study subjects had dry mouth or nose and difficult sleeping; however, it was significantly reduced at $6^{\text {th }}$ month (Table 3 ). The side effects of CPAP

Table 3. Auto-CPAP therapy adherence and side effects at $3^{\text {rd }}$ and $6^{\text {th }}$ month of study subjects.

\begin{tabular}{|c|c|c|c|}
\hline Parameter & At 3 months ( $n=136)$ & At 6 months $(n=134)$ & $p$ \\
\hline $\begin{array}{l}\text { Days without auto-CPAP usage at night } \\
\text { Accumulated days/month, day, 95\%CI (min - max) } \\
\text { Percentage of subjects, } \%\end{array}$ & $\begin{array}{c}4.3 \pm 1.4 \\
3.9-4.8(3-6) \\
20.5\end{array}$ & $\begin{array}{l}3.5 \pm 1.2 \\
3.1-3.9(2-5) \\
\quad 8.8\end{array}$ & $\begin{aligned} & N S \\
< & 0.01\end{aligned}$ \\
\hline $\begin{array}{l}\text { Days with auto-CPAP usage at night } \\
\text { Accumulated days/month, days, 95\%CI (min - max) } \\
\\
\geq 5 \text { h/night, \% subjects/month } \\
\text { 4-5 h/night, \% subjects/month } \\
3-4 \text { h/night, \% subjects/month }\end{array}$ & $\begin{array}{c}25.4 \pm 2.2 \\
24.1-26.5(22-30) \\
64 \pm 5 \\
28 \pm 3 \\
8 \pm 2\end{array}$ & $\begin{array}{c}26.6 \pm 1.8 \\
25.2-27.4(24-0) \\
67 \pm 6 \\
39 \pm 4 \\
4 \pm 1\end{array}$ & $\begin{array}{l}\text { NS } \\
\text { NS } \\
<0.05 \\
\text { NS }\end{array}$ \\
\hline $\begin{array}{l}\text { Hours of auto-CPAP usage per night } \\
\text { Min, hours } \\
\text { Max, hours } \\
\text { Average, hours, } \\
\text { 95\%CI (min - max) }\end{array}$ & $\begin{array}{c}2.3 \pm 0.4 \\
7.8 \pm 1.6 \\
5.2 \pm 2.2 \\
4.6-5.9(2-10)\end{array}$ & $\begin{array}{c}3.8 \pm 0.5 \\
8.6 \pm 1.5 \\
6.5 \pm 2.4 \\
5.7-7.2(3-10)\end{array}$ & $\begin{array}{l}<0.05 \\
\text { NS } \\
<0.05\end{array}$ \\
\hline $\begin{array}{l}\text { Attained auto-CPAP pressure during sleep } \\
\text { Min, } \mathrm{cmH}_{2} \mathrm{O} \\
\text { Max, } \mathrm{CmH}_{2} \mathrm{O} \\
\text { Average, } \mathrm{cmH}_{2} \mathrm{O}, 95 \% \mathrm{CI} \text { (min - max) }\end{array}$ & $\begin{array}{c}5.3 \pm 1.2 \\
16.4 \pm 4.6 \\
12.7 \pm 6.8 \\
10.3-14.6(4-20)\end{array}$ & $\begin{array}{c}5.8 \pm 1.6 \\
15.2 \pm 5.4 \\
11.5 \pm 6.9 \\
9.4-13.6(4-18)\end{array}$ & $\begin{array}{l}\text { NS } \\
\text { NS } \\
\text { NS }\end{array}$ \\
\hline $\begin{array}{l}\text { Respiratory events under auto-CPAP } \\
\text { OA, number/h } \\
\text { Hypopnea, number/h } \\
\text { AHI, number/h }\end{array}$ & $\begin{array}{l}14 \pm 6 \\
10 \pm 4 \\
12 \pm 6\end{array}$ & $\begin{array}{l}8 \pm 4 \\
6 \pm 3 \\
7 \pm 3\end{array}$ & $\begin{array}{c}<0.05 \\
\text { NS } \\
<0.05\end{array}$ \\
\hline $\begin{array}{l}\text { Auto-CPAP related side effects } \\
\text { Dry mouth or nose } \\
\text { Nasal congestion } \\
\text { Dry eyes } \\
\text { Discomfort breathing } \\
\text { Claustrophobia } \\
\text { Aerophagia or flatulence } \\
\text { Skin marks or rashes } \\
\text { Difficult sleeping }\end{array}$ & $\begin{array}{c}78.6 \\
13.2 \\
11.0 \\
25.7 \\
1.4 \\
7.3 \\
41.1 \\
65.4\end{array}$ & $\begin{array}{c}32.0 \\
11.9 \\
10.4 \\
16.0 \\
0.7 \\
6.7 \\
20.8 \\
36.1\end{array}$ & $\begin{array}{l}<0.001 \\
\mathrm{NS} \\
\mathrm{NS} \\
<0.05 \\
\mathrm{NS} \\
\mathrm{NS} \\
<0.001 \\
<0.001\end{array}$ \\
\hline
\end{tabular}

CPAP, continuous positive pressure; $\mathrm{CI}$, confidence interval; $\mathrm{OA}$, obstructive apnea; $\mathrm{AHI}$, apnea-hypopnea index. 
therapy and adherence were also reported in previous studies $[32,33]$. Finally, at the end of the study (6 months), there was $96.4 \%$ (134/139) of study subjects who continued to use autoCPAP at night. In the Home PAP Study, Rosen et al. [19] showed that $97 \%$ of OSA patients treated with auto-adjusting CPAP completed month 1 visits, $87 \%$ completed month 3 visits, and $84 \%$ completed both visits. These authors concluded that autoadjusting CPAP increased access to treatment with the potential to decrease healthcare expenditures and patient burden.

Recently, AASM (American Academy of Sleep Medicine) recommends positive airway pressure (PAP) therapy be initiated by using either auto-PAP (APAP) at home or in-laboratory PAP titration in adults with OSA and no significant comorbidities [16]. The ASSM clinical guidelines have stated that the potential benefits of using APAP in the home setting include lower cost, reduced time away from home, faster initiation of treatment and greater access to care [16]. Previous studies also suggested the use of auto-CPAP as an alternative method for laboratory-titrating CPAP therapy [34,35].

The present study has some important limitations, namely due to the small number of study subjects, short-term follow up, and lack of control group treated with in-laboratory titration CPAP therapy. Therefore, more studies about the role and benefits of auto-CPAP therapy in patients with moderate-to-severe OSA should be realized in the near future to evaluate and predict the long-term adherence and quality of life of auto-CPAP therapy in this population.

\section{Conclusions}

Auto-CPAP therapy has a beneficial role in the treatment of Vietnamese patients with severe OSA. The adherence of autoCPAP therapy in short term follow up is promising in the majority of patients with severe OSA. However, more longitudinal cohort studies on auto-CPAP therapy in patients with severe OSA should be instituted to confirm the efficacy of this treatment.

\section{Acknowledgements}

The authors would like to thank all the Member of Research Centers and Sleep Lab Center of Lam Dong Medical College for their contribution to this work.

\section{List of abbreviations}

AASM, American Academy of Sleep Medicine; AHI, apneahypopnea index; ARI, arousal index; BMI, body mass index; DBP, diastolic blood pressure; $L D L$, low density cholesterol; LFT, lung function testing; OSA, obstructive sleep apnea; PAP, positive airway pressure; PSG, polysomnography; SBP, systolic blood pressure.

\section{References}

1. Peppard PE, Young T, Barnet JH, Palta M, Hagen EW, Hla KM. Increased prevalence of sleep-disordered breathing in adults. Am J Epidemiol 2013;177:1006-14.

2. Mirrakhimov AE, Sooronbaev T, Mirrakhimov EM. Prevalence of obstructive sleep apnea in Asian adults: a systematic review of the literature. BMC Pulm Med 2013;13:10.

3. Duong-Quy S, Dang Thi Mai K, Tran Van N, Nguyen Xuan
Bich H, Hua-Huy T, Chalumeau F, et al. Study about the prevalence of the obstructive sleep apnoea syndrome in Vietnam. Rev Mal Respir 2018;35:14-24.

4. Dempsey JA, Veasey SC, Morgan BJ, O'Donnell CP. Pathophysiology of sleep apnea. Physiol Rev 2010;90:47-112.

5. Del Ben M, Fabiani M, Loffredo L, Polimeni L, Carnevale R, Baratta $F$, et al. Oxidative stress mediated arterial dysfunction in patients with obstructive sleep apnoea and the effect of continuous positive airway pressure treatment. BMC Pulm Med 2012;12:36.

6. Jurado-Gámez B, Fernandez-Marin MC, Gómez-Chaparro JL, Muñoz-Cabrera L, Lopez-Barea J, Perez-Jimenez F, et al. Relationship of oxidative stress and endothelial dysfunction in sleep apnoea. Eur Respir J 2011;37:873-9.

7. Epstein LJ, Kristo D, Strollo PJ Jr, Friedman N, Malhotra A, Patil SP, et al. Adult Obstructive Sleep Apnea Task Force of the American Academy of Sleep Medicine. Clinical guideline for the evaluation, management and long-term care of obstructive sleep apnea in adults. J Clin Sleep Med 2009;5:263-76.

8. Qaseem A, Holty JC, Owens DK, Dallas P, Starkey M, Shekelle P. Management of obstructive sleep apnea in adults: A clinical practice guideline from the American College of Physicians. Ann Intern Med 2013;159:471-83.

9. McDaid C, Durée KH, Griffin SC, Weatherly HL, Stradling JR, Davies RJ, et al. A systematic review of continuous positive airway pressure for obstructive sleep apnoea-hypopnoea syndrome. Sleep Med Rev 2009;13:427.

10. Sawyer AM, Gooneratne NS, Marcus CL, Ofer D, Richards KC, Weaver TE. A systematic review of CPAP adherence across age groups: clinical and empiric insights for developing CPAP adherence interventions. Sleep Med Rev 2011;15:343-56.

11. Weaver TE, Maislin G, Dinges DF, Bloxham T, George CF, Greenberg H, et al. Relationship between hours of CPAP use and achieving normal levels of sleepiness and daily functioning. Sleep 2007;30:711-9.

12. McEvoy RD, Antic NA, Heeley E, Luo Y, Ou Q, Zhang X, et al. CPAP for Prevention of Cardiovascular Events in Obstructive Sleep Apnea. N Engl J Med 2016;375:919.

13. Gurubhagavatula I, Sullivan S, Meoli A, Patil S, Olson R, Berneking M, et al. Management of obstructive sleep apnea in commercial motor vehicle operators: Recommendations of the AASM Sleep and Transportation Safety Awareness Task Force. J Clin Sleep Med 2017;13:745.

14. Morgenthaler TI, Deriy L, Heald JL, Thomas SM. The evolution of the AASM clinical practice guidelines: another step forward. J Clin Sleep Med 2016;12:129-35.

15. Kapur VK, Auckley DH, Chowdhuri S, Kuhlmann DC, Mehra $\mathrm{R}$, Ramar K, et al. Clinical practice guideline for diagnostic testing for adult obstructive sleep apnea: an American Academy of Sleep Medicine clinical practice guideline. J Clin Sleep Med 2017; 13:479-504.

16. Patil SP, Ayappa IA, Caples SM, Kimoff RJ, Patel SR, Harrod CG. Treatment of adult obstructive sleep apnea with positive airway pressure: An American Academy of Sleep Medicine clinical practice guideline. J Clin Sleep Med 2019;15:335-43.

17. McArdle N, Singh B, Murphy M, Gain KR, Maguire C, Mutch $\mathrm{S}$, et al. Continuous positive airway pressure titration for obstructive sleep apnoea: automatic versus manual titration. Thorax 2010;65:606-11.

18. Hui DS, Ng SS, Tam WWS. Home-based approach is noninferior to hospital-based approach in managing patients with suspected obstructive sleep apnoea syndrome. Am J Respir Crit Care Med.2018;197:1233-4. 
19. Rosen CL, Auckley D, Benca R, Foldvary-Schaefer N, Iber C, Kapur V, et al. A multisite randomized trial of portable sleep studies and positive airway pressure autotitration versus laboratory-based polysomnography for the diagnosis and treatment of obstructive sleep apnea: the HomePAP study. Sleep 2012;35:757-67.

20. Johns MW. Sleepiness in different situations measured by the Epworth Sleepiness Scale. Sleep 1994;17:703-10.

21. Pichot P, Brun JP. [Questionnaire bref d'auto-évaluation des dimensions dépressive, asthénique et anxieuse].[Article in French]. Ann Mes-Psychol 1984;142:862-5.

22. Miller MR, Crapo R, Hankinson J, Brusasco V, Burgos F, et al. General considerations for lung function testing. Eur Respir J 2005;26:153-61.

23. Davies CW, Crosby JH, Mullins RL. Case-control study of 24 hour ambulatory blood pressure in patients with obstructive sleep apnoea and normal matched control subjects. Thorax 2000;55:736-40.

24. Parati G, Lombardi C, Hedner J. Position paper on the management of patients with obstructive sleep apnea and hypertension: joint recommendations by the European Society of Hypertension, by the European Respiratory Society and by the members of European COST (COoperation in Scientific and Technological research) ACTION B26 on obstructive sleep apnea. J Hypertens 2012;30:63346.

25. Pamidi S, Wroblewski K, Broussard J, Day A, Hanlon EC, Abraham V, et al. Obstructive sleep apnea in young lean men: impact on insulin sensitivity and secretion. Diabetes Care 2012;35:2384-9.

26. Borel AL, Monneret D, Tamisier R, Baguet JP, Faure P, Levy $\mathrm{P}$, et al. The severity of nocturnal hypoxia but not abdominal adiposity is associated with insulin resistance in non-obese men with sleep apnea. PLoS One 2013;8:e71000.
27. Montesi SB, Edwards BA, Malhotra A, Bakker JP. The effect of continuous positive airway pressure treatment on blood pressure: a systematic review and meta-analysis of randomized controlled trials. J Clin Sleep Med 2012;8:587-96.

28. Fava C, Dorigoni S, Dalle Vedove F, Danese E, Montagnana M, Guidi GC, et al. Effect of CPAP on blood pressure in patients with OSA/hypopnea: a systematic review and metaanalysis. Chest 2014;145:762-71.

29. Schein AS, Kerkhoff AC, Coronel CC, Plentz RD, Sbruzzi G. Continuous positive airway pressure reduces blood pressure in patients with obstructive sleep apnea; a systematic review and meta-analysis with 1000 patients, J Hypertens 2014;32:176273.

30. Garcia JM, Sharafkhaneh H, Hirshkowitz M, Elkhatib R, Sharafkhaneh A. Weight and metabolic effects of CPAP in obstructive sleep apnea patients with obesity. Respir Res 2011;12:80.

31. Kong DL, Qin Z, Wang W, Pan Y, Kang J, Pang J. Association between obstructive sleep apnea and metabolic syndrome: a meta-analysis. Clin Invest Med 2016;39:E161-72.

32. Weaver TE. Don't start celebrating - CPAP adherence remains a problem. J Clin Sleep Med 2013;9:551-2.

33. Weaver TE, Sawyer AM. Adherence to continuous positive airway pressure treatment for obstructive sleep apnoea: implications for future interventions. Ind J Med Res 2010;131:245-58.

34. Fletcher EC, Stich J, Yang KL. Unattended home diagnosis and treatment of obstructive sleep apnea without polysomnography. Arch Fam Med 2000;9:168-74.

35. Masa JF, Jimenez A, Duran J, Capote F, Monasterio C, Mayos $\mathrm{M}$, et al. Alternative methods of titrating continuous positive airway pressure: a large multicenter study. Am J Respir Crit Care Med 2004;170:1218-24.

Received for publication: 29 August 2019. Accepted for publication: 5 December 2019.

This work is licensed under a Creative Commons Attribution-NonCommercial 4.0 International License (CC BY-NC 4.0).

CCopyright: the Author(s), 2020

Licensee PAGEPress, Italy

Multidisciplinary Respiratory Medicine 2020; 15:468

doi:10.4081/mrm.2020.468 